\title{
A enfermeira interagindo e se relacionando: o contexto do cuidado de enfermagem em unidade semi-intensiva
}

\author{
The nurse interacting and relating: the context of nursing care in a semi-intensive unit \\ La enfermera interactuando y relacionándose: el contexto de los cuidados \\ de enfermería en una unidad semi-intensiva
}

\section{Marcos Paulo de Oliveira Lima', Consuelo Helena Aires de Freitas'}

' Universidade Estadual do Ceará, Mestrado Acadêmico em Cuidados Clínicos em Saúde. Fortaleza-CE, Brasil.

Submissão: 10-10-2010 Aprovação: 04-01-2012

\section{RESUMO}

Este estudo teve como objetivo compreender o significado do cuidado de enfermagem para enfermeiras do contexto hospitalar. Trata-se de uma pesquisa qualitativa, fundamentada nos pressupostos teóricos e metodológicos do interacionismo simbólico. Foi realizada em unidade semi-intensiva de um hospital público terciário na cidade de Fortaleza/CE. Participaram onze enfermeiras. Utilizou-se a entrevista semiestruturada e a observação de campo simples para a coleta de dados. Foi realizada a análise categorial temática no tratamento dos dados. Os aspectos éticos foram respeitados. Apreendeu-se que o cuidado de enfermagem significa o estabelecimento de relacionamentos interpessoais da enfermeira com os demais profissionais de saúde, os acompanhantes e pacientes. Compreendeu-se que, para enfermeiras do contexto hospitalar, o cuidado de enfermagem significa interação social com as pessoas.

Descritores: Cuidados de enfermagem; Assistência hospitalar; Relações interpessoais.

\section{ABSTRACT}

This study aimed to understand the meaning of nursing care to nurses in the hospital. This is a qualitative research, based on theoretical and methodological assumptions of symbolic interaction. It was performed in a semi-intensive unit of a tertiary public hospital in Fortaleza-CE, Brazil. Eleven nurses participated on it. For data collection, it was used semi-structured interviews and field observation simple and, in data processing it was performed thematic category. The ethical aspects have been respected. It was observed that the nursing care means the establishment of the nurse's interpersonal relationships with other health professionals, patients and their accompanying persons. It was understood that, for nurses of the hospital, nursing care means social interaction with people.

Key words: Nursing Care; Hospital Care; Interpersonal Relations

\section{RESUMEN}

Este estudio tuvo como objetivo comprender el significado de los cuidados de enfermería para las enfermeras en el contexto hospitalario. Esta es una investigación cualitativa, basada en los supuestos teóricos y metodológicos de la interacción simbólica. Se realizó en la unidad semi-intensiva de un hospital público terciario en Fortaleza-CE, Brasil. Once enfermeras participaran en el estudio. Se utilizó una entrevista semi-estructurada y simple observación de campo. Utilizó-se el análisis categorial de los datos. Los aspectos éticos han sido respetados. Observó-se que la atención de enfermería se da mediante el establecimiento de relaciones interpersonales de la enfermera con otros profesionales de la salud, pacientes y sus acompanhates. Se entendió que, para las enfermeras, en el contexto hospitalario, los cuidados de enfermería significan la interacción social con las personas. Palabras clave: Atención de Enfermería; Atención Hospitalaria; Relaciones Interpersonales.

Trabalho realizado com apoio da Fundação Cearense de Apoio ao Desenvolvimento Científico e Tecnológico - FUNCAP. Fortaleza-CE, Brasil. 


\section{INTRODUÇÃO}

Durante nossas experiências profissionais, observamos que o cuidado de enfermagem vem sendo questionado e discutido quanto a sua especificidade no âmbito da profissão, o que tem motivado a geração de pesquisas por parte dos enfermeiros no serviço e ensino.

A discussão acerca do "cuidado humano" na área da saúde remonta a história da evolução humana e sua relação com o ato de cuidar, em que os seres humanos desenvolveram formas e expressões de cuidar, atitudes e sentimentos de não cuidado $^{(1)}$, colocando em pauta os paradoxos e ambiguidades entre esses comportamentos, cuidado e não cuidado.

No âmbito da Enfermagem, apreendemos que as questões discutidas acerca do cuidado de enfermagem se dão a partir do momento em que a existência de algo ou alguém possui importância para o outro ${ }^{(2)}$. Na lógica do ciclo vital, o cuidado de enfermagem se desenvolve seguindo as especificidades nas fases da vida até a morte. É uma necessidade humana essencial ${ }^{(3)}$, sendo o fundamento para qualquer interpretação do ser humano. Ele significa desvelo, solicitude, zelo e atenção(4). As definições são bastante pertinentes ao aproximar a característica humana do cuidado.

O cuidar passou a ser o constructo teórico central para a Enfermagem ${ }^{(5)}$. A enfermagem descrita como profissão de ajuda, complexa e multifacetada, constituída por ampla variedade de elementos, em sua composição e em sua prática, incorporou o cuidar. Historicamente, os enfermeiros cuidam bem dos clientes e de forma organizada, sendo esta a essência da Enfermagem, que envolve ajuda, atenção, respeito, amor e compreensão mútua ${ }^{(6)}$, sendo foco de atenção de estudos e pesquisas na evolução da profissão.

Torna-se evidente nas pesquisas acerca do cuidado de enfermagem, a necessidade de se intensificar e ampliar os estudos sobre a temática para a profissão para melhor consolidar a prática profissional pautada no cuidado. Refletir essa dimensão possibilita instrumentalizar o cuidador para auxiliar o outro a encontrar seus próprios caminhos. É preciso ampliar os conhecimentos teórico-científicos, a fim de criar um corpo próprio de conceitos que embasem o cuidado de enfermagem ${ }^{(7)}$.

Dentro do corpo de conhecimento da Enfermagem existem teorias que privilegiam a abordagem interativa-humanística das ações. A Enfermagem humanística preocupa-se com o ser, auxiliando-o a aumentar a possibilidade de serem feitas escolhas responsáveis, visando o desenvolvimento do bem-estar ${ }^{(10)}$. Ela enfoca o todo e enxerga além da categorização das partes. A enfermagem fenomenológica, tem o intuito de compreender e descrever as situações vivenciais do enfermeiro e cliente, de forma que ambos possam estar de maneira humana ${ }^{(11)}$.

Acreditamos que o cuidado de enfermagem consiste em uma forma de ser, de viver, de expressar. É uma postura ética e estética frente ao mundo. É um compromisso com o estar-no-mundo e contribuir com o bem-estar geral, na promoção das potencialidades, da dignidade humana; é contribuir na construção da história, do conhecimento e da vida ${ }^{(8)}$.
Para a presente pesquisa, evidenciamos o cuidado de enfermagem na perspectiva interacionista, em que buscamos conceitos existentes na Enfermagem que expressam as várias facetas para o cuidado na dimensão interativa: o cuidado de enfermagem compreendendo comportamentos e atitudes demonstrados nas ações que lhe são pertinentes, e desenvolvidos com competência no sentido de favorecer as potencialidades das pessoas para manter ou melhorar a condição humana no processo de viver e morrer ${ }^{(8)}$. $\mathrm{O}$ ato de cuidar implica no estabelecimento da relação entre sujeitos, profissional e cliente ${ }^{(9)}$.

Consideramos que o espaço intersubjetivo estabelecido entre ambos é permeado por emoções, significados e sentidos. Assim, destacamos o cuidar como relação, interação entre os sujeitos. As diversas situações de cuidado, aproximando aqui o ambiente hospitalar, implicam no estabelecimento de relações entre as pessoas. Estudar o cuidado de enfermagem ao cliente requer entender o próprio cuidado e os sujeitos nele envolvidos.

Assim, a interação tornou-se um conceito central nesse estudo. No estabelecimento das relações cuidativas, ela é entendida como o encontro entre o enfermeiro e o cliente no momento do cuidado, e esse encontro influencia mutuamente os participantes, implica em comunicação, diálogo e convivência ${ }^{(12)}$.

Compreendemos que o ato de cuidar do enfermeiro constitui-se de instrumento subjetivo, a ação. E ainda sendo a enfermagem "(...) profissão pela qual o ser enfermeiro realiza interações com o ser cuidado (...) considerando as suas necessidades, transformando-o e se transformando por meio de uma relação de cuidado"(13). Esse conceito de abordagem humanística designa uma atenção à saúde interessada no sentido existencial da experiência do adoecimento, ou seja, para além dos procedimentos técnicos ${ }^{(14)}$.

No processo de interação, a construção da ação faz a relação, no tocante de que as ações interativas vão sendo modificadas e re-construídas, isto quando partimos do principio de que os seres humanos são singulares, e estão intrincados com o que os outros fazem.

A pesquisa é relevante por estudar ações, comportamentos e sentimentos de enfermeiros no contexto do cuidado de enfermagem, contribuindo para nortear a reflexão e elaboração do cuidado nos campo de prática e do ensino, na discussão das relações na perspectiva interacional. O objetivo consistiu em compreender o significado do cuidado de enfermagem para a enfermeira no contexto hospitalar.

\section{A PERSPECTIVA TEÓRICA E METODOLÓGICA DO ESTUDO}

Trabalhar com o significado requereu a utilização de uma abordagem teórica que nos possibilitasse apreender esse nível da realidade. Estabelecemos o interacionismo simbóli$\mathrm{Co}^{(15)}$ como referencial teórico e metodológico, sobre o qual foi construído este estudo, permeando-o desde o processo de busca das informações, até a análise das mesmas.

O Interacionismo Simbólico, uma perspectiva da psicologia social, teve sua origem principalmente no pensamento de 
George Herbert Mead, um professor de filosofia da Universidade de Chicago, que viveu no período de 1863 a 1931. A visão de Mead foi influenciada pela escola pragmática, pela teoria da evolução de Darwin, e pelo behaviorismo.

O idealizador da teoria não teve tempo de publicar suas ideias teóricas, deixando apenas notas de aulas e conteúdo de trasmissão oral para seus alunos. A principal obra de Mead é uma publicação póstuma intitulada Mind, Self and Society (1934), que reune as principais ideias interacionistas.

Para Mead os seres humanos possuem mente e consciência; eles vivem em mundo de objetos preexistentes e auto-constituídos; seu comportamento consiste de resposta a tais objetos; e a vida grupal humana consiste de associação de tais organismos que reagem ${ }^{(15)}$.

No entanto, foi Herbert Blumer, sociólogo, ex-aluno e discípulo de Mead, que apresentou de forma sistemática os pressupostos básicos da abordagem interacionista. As idéias de Blumer, que manteve a continuidade da abordagem humanística de Mead, foram publicadas no livro: Symbolic interactionism: perspective and method (1969). Neste livro Blumer afirma conceitos teóricos e metodológicos do interacionismo simbólico, entendida numa abordagem descritiva ao estudo do grupo humano e da vida humana. Segundo Blumer a teoria interacionista possui três premissas básicas quais sejam:

1. Os seres humanos agem em relação às coisas tomando por base o significado que essas coisas têm para ele;

2. O significado de tais coisas, às vezes, surge de uma interação social que a pessoa tem com seus iguais;

3. Esses significados são lidados, e são modificados, num processo interpretativo, utilizado pela pessoa para lidar com as coisas que ele encontra.

O interacionismo simbólico está fundamentado, ainda, em idéias básicas, ou "imagens de raízes" como chama Blumer. Estas idéias se referem à natureza de: grupos humanos ou sociedade; interação social; objetos; o ser humano como ator; a ação humana e a interconexão das linhas de ação dos seres humanos. Aproximamos essas idéias conforme apresentadas Blumer.

Grupos humanos e a sociedade existem em ação e devem ser vistos em termos de ação. Grupos humanos são visto como consistindo que estão engajados em uma ação. Ação consiste em atividades múltiplas que os indivíduos realizam em sua vida.

Uma sociedade coniste de indivíduos que interagem uns com os outros. As atividades ocorrem predominantemente em resposta a um ou outro ou em relação ao outro. Para a teoria interacionista a interação social é de vital importância, poisa conduta humana se forma através dela.

A natureza existe para os seres humanos e para seus grupos e são compostos de objetos ${ }^{(15)}$, que são o produto de interação simbólica. O objeto é qualquer coisa que possa ser apontada ou referida; ele pode ser físico, social e abstrato. Mais importante é a afirmação de que um objeto consiste de significado, que ele tem para a pessoa para quem ele é objeto. Esse significado estebelece a forma na qual a pessoa vê o objeto, a forma pela qual ela age, e a forma pela qual ela fala dele. Assim, um objeto pode ter um significado diferente para indivíduos diferentes.

O ser humano deve ser visto como um ator $^{(15)}$, como um organismo que não somente responde aos outros, mas como aquele que faz indicações para outros e interpretam suas indicações. Este indivíduo humano confronta o mundo, e assim ele o interpreta a fim de agir. A sua ação humana tem que ser construída. Para agir este ser humano considera as várias coisas que ele observa, assumindo uma linha de conduta tomando por base como ele as interpreta.

Complementarmente, o comportamento na sociedade consiste de indivíduos adaptando a suas linhas de ação uma a outra. A vida do grupo humano consiste na combinação de linhas de ação com cada um dos seus membros de seu grupo $^{(15)}$.

No âmbito da Enfermagem este referencial teórico e metodológico tem sido utilizado com sucesso. A teoria dá suporte para a ampliação do conhecimento na área da enfermagem, para a construção de ações e estratégias voltadas para um relacionamento interativo e humanizado entre as pessoas ${ }^{(16)}$.

\section{METODOLOGIA}

Trata-se de um estudo qualitativo ${ }^{(17)}$, fundamentado nos presupostos metodológicos do interacionismo simbólico. Esta abordagem apresentou-se como suporte para o estudo do objeto, possibilitando a compreensão dos significados do cuidado de enfermagem para enfermeiras no contexto hospitalar.

O método qualitativo fornece uma compreensão profunda dos fenômenos sociais investigados, enfatizando as especificidades dos fenômenos em termos de suas origens e de sua razão de ser, dentro do contexto social ${ }^{(18)}$.

O estudo foi realizado em um hospital de grande porte e especializado no atendimento às pessoas com doenças cardio-circulatórias. A instituição, situada em Fortaleza, Estado do Ceará, é gerenciada pela Secretaria da Saúde do Estado (SESA) e atende pacientes dos 184 municípios cearenses, além de receber pessoas das regiões Norte e Nordeste do país. Todo o atendimento realizado por esta unidade estadual de saúde é via Sistema Único de Saúde/SUS.

A escolha pelo referido campo se deu devido ao fato de que o hospital é uma instituição de referência nacional, estadual e regional de atendimento em saúde, configurando-se como uma das principais instituições de assistência em saúde do estado do Ceará. A pesquisa concentrou-se, mais especificamente, na unidade semi-intensiva, um dos setores da instituição. Esta possui quatorze leitos para pacientes que requerem cuidados semi-intensivos, sejam da clínica ou da cirurgia.

A população estava constituída por quinze enfermeiras assistenciais, distribuídas na escala diurna e noturna da referida unidade. Como critério de inclusão, definimos que a enfermeira deveria pertencer a escala de serviço diurna ou noturna da unidade há pelo menos seis meses - acreditando que seria necessário esse tempo para que a profissional estevesse habituado com o setor, e pudesse falar sobre o cuidado que ela realizava naquele contexto. 
Aplicados os critérios de exclusão, participaram efetivamente do estudo 11 (onze) enfermeiras assistenciais. Por se tratar de um estudo qualitativo, a amostra foi definida pelo critério de saturação teórica, ou seja, foram coletados os dados até a saturação das informações, onde percebemos que temas comuns começaram a se repetir e novas percepções não mais aparecíam, respondendo aos objetivos propostos por este estudo ${ }^{(19)}$.

A partir dos ensinamentos metodológicos apresentados por Blumer (1969), utilizamos duas técnicas para coletar as informações: a entrevista semiestruturada gravada e a técnica da observação de campo, com a finalidade de apreender a realidade e atingir o objetivo proposto.

A observação de campo permitiu um acompanhamento mais prolongado e minucioso das situações diárias, ou seja, do mundo empírico. Para está técnica utilizamos um "Diário de campo". Nele foram registradas todas as observações e reflexões que realizamos sobre as expressões verbais e ações dos sujeitos, descrevendo-as e fazendo comentários críticos. Participaram desta técnica as onze enfermeiras.

A estrevista semiestruturada foi realizada com sete enfermeiras, escolhidas aleatoriamente entre as onze participantes. Nelas solicitávamos: fale sobre o cuidado de enfermagem no hospital? Como você pratica o cuidado de enfermagem? Quais dificuldades e facilidades que você encontra quando está cuidando? Como você define o cuidado de enfermagem? E como você o vivencia neste hospital? O que significa para você o cuidado de enfermagem?

Na caracterização das participantes observamos o seguinte: uma é casada, uma é divorciada e 5 são solteiras. $O$ tempo de graduadas variou de 1 a 16 anos. O tempo que exerce a profissão variou de 8 meses a 16 anos. O tempo que trabalha na instituição variou de 8 meses a 6 anos. Quanto à existência de outro emprego observamos que 06 trabalhavam em outra instituição como enfermeiras, e apenas uma trabalhava somente na unidade pesquisada. Quanto à pós-graduação: uma possuia mestrado em cuidados clínicos, 3 eram especialistas - enfermagem do trabalho; enfermagem médico-cirúrgica e enfermagem em terapia intensiva -, e 3 não possuíam pós-graduação, estando matriculadas em cursos de especialização.

Após a fase de coleta de dados, as entrevistas foram transcritas e analisadas utilizando-se a análise categorial ${ }^{(20)}$. A análise de conteúdo é realizada a partir de três fases básicas ${ }^{(20)}$, as quais estão descriminadas a seguir: Pré-análise; Exploração do material e Tratamento dos resultados obtidos e interpretação.

Encaminhamos o projeto deste estudo para o Comitê de Ética em pesquisa do hospital campo da pesquisa. Iniciamos a coleta dos dados somente após recebimento do parecer favorável, sob o protocolo número 632/2009. Todas as participantes assinaram o termo de consentimento livre e esclarecido. Para preservar a identidade das participantes, utilizamos as letras E, N, F, R, M, A e G que compõem a palavra ENFERMAGEM.

\section{RESULTADOS E DISCUSSÃO}

Compreendemos o cuidado de enfermagem para as enfermeiras no cotexto hospitalar a partir da categoria temática: $A$ enfermeira interagindo e se relacionando - o contexto social. Esta categoria se divide em quatro subcategorias que expressam o significado outrora buscado.

\section{Relacionamento interpessoal com os profissionais do am- biente hospitalar}

Uma sociedade consiste de indivíduos que interagem uns com os outros. As atividades dos membros ocorrem predominantemente em respostas a um ou outro ou em relação ao outro $^{(15)}$. Nos depoimentos, observamos que as enfermeiras faziam referência ao trabalho em equipe. No setor pesquisado, a equipe de saúde é composta por: médicos, enfermeiros, fisioterapêuta, nutricionistas, assistentes sociais, técnicos e auxiliares de enfermagem. Complementam-na outros profissionais que não pertencem ao setor, mas estão à disposição para serem solicitados, como por exemplo, o odontólogo e o psicólogo. A assistência à saúde dos pacientes internados caracteriza-se como sendo multiprofissional, onde cada um participa com o seu conhecimento. Ao final, todos buscam assistir aos pacientes e, em muitos momentos, necessitam interagir uns com os outros, como destacamos nos depoimentos abaixo:

(...) afinal de contas, nós somos uma equipe multidisciplinar. Eu tenho meus conheciementos, o médico tem outros e unindo nosso conhecimento, vai tá dando (...) um cuidado melhor (...) tem essa interação com a equipe. (...) Quando eu faço a visita de manhã, vai o médico, o fisioterapêuta, as enfermeiras leito a leito, discutindo os casos (...) (A)

(...) vamos olhar alí com o médico (...) a gente tem que tá junto, em equipe né? É o médico, é uma nutricionista que chega aqui de manhã, vem me perguntar uma coisa e outra, e olha tá com uma ferida assim, tem como ajudar na nutrição?(...) (M)

A enfermeira está dentro do hospital para disponibilizar os cuidados de enfermagem aos pacientes. Nesse ambiente estão presentes outros profissionais com objetivos semelhantes. Nesse sentido, todos trabalham em prol dos pacientes. A enfermeira cuida, mas leva em consideração a conduta dos outros membros da equipe, ela interage com o médico, nutricionista e fisioterapêuta, sendo também solicitada por esses profissionais.

Há transmissão de informações, troca de conhecimentos entre os profissionais. Cada membro é detentor de saberes e fazeres próprios. E nesse relacionamento a enfermeira "ajuda e é ajudada". Nessa interação com os membros da equipe ocorre o cuidado de enfermagem aos pacientes. Ou seja, para cuidar a enfermeira interage com profissionais do ambiente hospitalar.

Nesse sentido, os seres humanos ao interagir uns com os outros têm que levar em conta o que os outros estão fazendo ou estão prestes a fazer; são forçados a dirigir sua própria conduta ou lidar com suas próprias situações em termos daquilo que levam em consideração(15).

Essa interação da enfermeira com a equipe ocorre constantemente, de dia e à noite. Observamos, também, o compromisso 
no cuidado. A enfermeira trabalhando à noite, cuidando dos pacientes, mesmo sem a presença do fisioterapêuta, assistente social e/ou nutricionista, passa o plantão para as colegas enfermeiras do dia, e transmite informações do estado de saúde para outros profissionais, visando à evolução do paciente, que nesse contexto tem o sentido de melhora no estado de saúde.

$\mathrm{Na}$ unidade pesquisada, existe uma reunião semanal com todos os profissionais da equipe de saúde. Nessa reunião eles dicutem as condutas terapêuticas que estão sendo realizadas, e outros assuntos pertinentes ao momento. Todos os profissionais vão de leito em leito e conversam sobre o estado de saúde dos pacientes, o tratamento, as melhoras ou as pioras. Nessa reunião, todos devem participar: médico, enfermeira, assistente social, fisioterapeuta, nutricionista, e quem mais estiver presente. Essa reunião foi referida pela participante $M$ :

Assim, a gente interage com o resto da equipe (...) toda semana tem a reunião (...) mas é na reunião que a gente decide muita coisa e na reunião todo mundo tem voto igual, a assistente social, é o médico, é a enfermeira (...)

Na reunião é onde se "decide muita coisa" e todos têm "voto igual". Essa frase mostra-nos a enfermeira interagindo com os membros da equipe de saúde e cuidando de seus pacientes, pois estão ajudando nas decisões que o médico ou demais profissionais estão tomando.

Essa interação da enfermeira com a equipe multidisciplinar traz o sentimento de confiança, como observamos no depoimento abaixo:

(...) eu acho que a confiança da minha chefia, do apoio que eu tenho, tanto da parte médica, como da parte da enfermagem. A interação que a gente tem com os médicos diaristas, eles confiam muito na gente, eles sabem que a gente tá aqui todo dia (...) (M)

A enfermeira do depoimento conhece os pacientes, ela fala com segurança sobre o estado de saúde deles e a conduta que foi estabelecida. Os médicos sabem que a enfermeira está na unidade quase todos os dias e confiam nela. A enfermeira percebe esse sentimento de confiança na interação com a equipe. Quando ela vai cuidar, interagindo com outros profissionais, ela percebe que eles confiam nela, apoiando-a. Então, ela cuida a partir da confiança dada pela interação.

A configuração de equipe de saúde, destacada nos depoimentos anteriores, é divergente, ora se mostrando como equipe integração, ora como equipe agrupamento ${ }^{(21)}$, no entanto sempre a partir do processo de interação com os demais profissionais da saúde. O projeto assistencial comum partilhado pelos profissionais, onde todos contribuem para a sua elaboração, ou na modificação, mostra a configuração da equipe integração. A comunicação exercida apenas como instrumentalização da técnica, com a sobreposição de conhecimentos disciplinares configura essa equipe como agrupamento.

Outro aspecto relevante, que emergiu dos depoimentos, foi o relacionamento interpessoal que a enfermeira estabelece as demais pessoas. Sabemos que o processo de trabalho do enfermeiro se dá mediante as relações interpessoais com a equipe de saúde, equipe de enfermagem, profissionais de outros setores do hospital, pacientes, familiares, enfim, o enfermeiro de serviço, está sempre a frente do relacionamento interpessoal. O depoimento abaixo expressa a forma como concebe a relação com profissionais do setor de rouparia do hospital.

(...) eu acho muito importante na nossa profissão é você ter assim um relacionamento interpessoal muito bom (...). Aí vai faltar lençol, eu já conheço o pessoal da rouparia aí eu ligo e a gente negocia (...) você tem amizade lá na UTI (...) me apoia (...) as unidades são muito solicitas, umas contam com as outras. (...) É uma espécie de parceria né (...) (A)

No dia-a-dia de trabalho na unidade, a enfermeira realiza muitas atividades, além dos cuidados diretos e indiretos com pacientes. Por exemplo, além de solicitar roupas para os pacientes ao setor de rouparia; gerencia o recebimento dos medicamentos da farmácia; as solicitações do setor de manutenção; realização de exames de laboratório; da radiologia, enfim, para que tenha êxito no desenvolvimento do processo de trabalho de permeiam o cuidado ao paciente, ela expressa que estabelece esse relacionamento amistosamente, fazendo amizades, mantendo um "coleguismo". Pelo depoimento, ela já conhece os profissionais da rouparia, e eles a conhecem. Isto facilita essa relação interpessoal positiva, que contribui para o cuidado de enfermagem.

\section{Interação com a equipe de enfermagem}

A enfermeira no ambiente pesquisado possui uma equipe de enfermagem constituída por sete técnicos ou auxiliares de enfermagem. Alguns cuidados de enfermagem são privativos do enfermeiro, outros são realizados por técnicos e auxiliares de enfermagem, embora sejam compartilhados por toda a equipe de enfermagem. A enfermeira exerce, também, o papel de supervisora desta equipe sendo solicitada e solicitando ações e realização de cuidados, tendo como finalidade os cuidados de enfermagem. Observamos a interação da enfermeira com os membros da equipe de enfermagem nos depoimentos a seguir.

Eu gosto muito de trabalhar aqui, eu acho que a relação com as pessoas é muito boa (...) principalmente com os auxiliares, então assim (...) eu acho que é um ponto positivo da relação, é isso. É porque você se sente bem acolhido. (R)

Eu tento trabalhar também para no cuidado, junto com meus auxiliares, com quem eu trabalho, interagindo com eles, que eu possa também ter informações pra eu cuidar melhor. (...) eu procuro estar com eles (...) eu procuro trabalhar junto com eles. (N)

Apreendemos que a enfermeira se sente acolhida por sua equipe e procura trabalhar junto com ela, pois dessa forma acredita cuidar melhor de seus pacientes. A interação da enfermeira com a equipe de enfermagem, como dimensão do processo de cuidar, está presente no cotidiano do ambiente hospitalar, convergindo para uma convivência harmônica, 
permeada por ajuda mútua, o que constroi vínculos de aproximação, gerando bem-estar em cada um dos envolvidos e a possibilidade de crescimento $^{(22)}$. A enfermeira cuida, mas conta com os técnicos e auxiliares de enfermagem para esse cuidado, pois eles trabalham junto, ajudando-se e ajudando-a.

A interação dentro da equipe de enfermagem caminha também em outra direção, como pudemos observar no depoimento abaixo:

Eu acho que também uma coisa do cuidado de enfermagem, que, também tem que ter, é da nossa parte como profissional e como enfermeiro, de orientar, eu acho que orientar (...) os auxiliares com quem a gente trabalha, eu acho que o cuidado de enfermagem também envolve isso. (N)

A enfermeira gerencia as atividades e supervisiona os cuidados realizados pela equipe de enfermagem. Percebemos que se estabelece uma relação pedagógica, pois está atenta a atuação dos técnicos e auxiliares de enfermagem, no que devem fazer, havendo interação social entre eles. Nesse sentido, o interacionismo simbólico reconhece essa interação social como sendo de vital importância no comportamento humano ${ }^{(15)}$.

A unidade hospitalar em tratamento semi-intensivo, por vezes, recebe pacientes graves, com risco de morte, configurando-se como tratamento intensivo. Nesse contexto, a enfermeira ensina aos profissionais de nível médio porque ela é a supervisora da equipe. E nesse processo de ensino-aprendizagem, o relacionamento interpessoal se estabelece com a divisão social das atividades no cuidado de enfermagem.

O trabalho em equipe possibilita a construção de relações humanas e sociais saudáveis, pois quando a equipe interage promovem crescimento e amadurecimento aos profissionais envolvidos $^{(23)}$. Ou seja, o trabalho da enfermeira com a sua equipe de enfermagem, visualizando o cuidado de enfermagem ao paciente, por meio do estabelecimento de relações sociais, promove o crescimento e amadurecimento de todos os envolvidos.

Percebemos que existe uma compreensão do outro nesse relacionamento interpesssoal, pois quando um dos membros da equipe não sabe como agir dentro do ambiente hospitalar, a enfermeira está alí, ajudando, ensinando, sendo amiga.

A vida de qualquer sociedade humana consiste necessariamente de um processo contínuo de adaptar-se com as outras atividades de seus membros ${ }^{(15)}$. Ou seja, a vida do grupo de enfermeiras da unidade semi-intensiva consiste de um processo contínuo de adaptar-se com as outras atividades de seus membros. Assim, ela interage ensinando e se adaptando ao que ela observa das outras pessoas.

\section{Interação da enfermeira com acompanhantes}

$\mathrm{Na}$ unidade da pesquisa cada paciente internado pode ter um acompanhante. Esse pode ser da família, ou não. Pode ser amigo, conhecido ou vizinho. Este fica na enfemaria, próximo ao paciente, ajudando-o. Muitas vezes, esses acompanhantes permanecem semanas dentro da unidade. Desta forma, a enfermeira interage com ele.
Observamos que, na realização dos cuidados, a enfermeira explica os procedimentos ao acompanhante. Algumas vezes ela solicita a ajuda deles quando vai realizar alguma atividade. Os técnicos de enfermagem quando vão banhar o paciente sempre solicitam a participação da família, para ajudar e também, como forma de aproximar esse acomapanhante familiar dos cuidados ao paciente. Pudemos observar como ocorre essa interação com a família nos seguintes depoimentos:

(...) é você conversar com a família do doente, porque (...) o familiar cuidador que tá alí na semi-intensiva, ele tá alí vendo o que você tá fazendo, quer dizer ele tá observando, quer dizer ele tá prestando atenção (...) (G)

Lá na semi-intensiva tem sido o diferencial, se dá a oportunidade (...) do acompanhante estar presente. (...) eu chego pra pessoa e tento explicar dentro de uma linguagem fácil (...) mas a minha postura é tá conversando com a família (...). Eu acho que a própria família se sente valorizada em estar interferindo nesse cuidado (...) (A)

Acreditamos que essas ações configuram-se como cuidados de enfermagem direcionados à família. A enfermeira cuida dos pacientes, mas também cuida do familiar acompanhante. Ela conversa e explica. Essas duas ações aparentemente simples são carregadas de significados para todos os envolvidos: para a enfermeira que percebe o sofrimento da família e tenta intervir de alguma forma, e para os familiares que, em alguns momentos, mesmo não entendendo o que esteja acontecendo com o seu ente querido que está internado, e recebe informações numa linguagem acessível de um profissional da saúde.

A enfermeira intervem porque ela percebe que os acompanhantes familiares estão sofrendo ao ver seu familiar doente, internado no hospital, muitas vezes com estado de saúde grave, intubados ou traqueostomizados, respirando com a ajuda do ventilador mecânico e com sondas e catéteres em todos os orifícios do corpo.

(...) têm-se também os cuidados com a família, aqui a gente vê que a família tá precisando mais do cuidado do que o próprio paciente (...) a família tá sofrendo, tá querendo perguntar, tá querendo saber (...) (E)

A família está em um ambiente, desconhecido para ela. Muitos equipamentos, muitas máquinas, muitos profissionais: médicos, enfermeiros, fisioterapêutas, asssistentes sociais, nutricionistas, técnicos e auxiliares de enfermagem. Todos diariamente entram na enfermaria e manipulam o seu familiar. Banham, fazem curativos, instalam dietas, colhem sangue para exames, dentre outros. A família está perto, vendo e observando. Ela fica inquieta, quer perguntar, que saber. Nesse contexto, a enfermeira interage com essa família, orientando, explicando, passando informações, como destacado nos depoimentos a seguir.

(...) e envolver a família (...) que lá na Semi a gente trabalha muito com a família (...) ela tá querendo saber o 
que tá acontecendo com o seu familiar, o quê que tão fazendo com ele (...) envolver a família fazendo algum tipo de orientação (...) e aí, é claro, que eu vou explicar em termos não científicos, mas em termos que eles possam entender. $(\mathrm{N})$

(...) aqui por ser uma UTI semi-intensiva, tem a oportunidade do acompanhante ficar com o paciente. A gente conversa, porque eles tiram as dúvidas (...) dar informações também é um tipo de cuidado (...) dar informação dentro do que a gente pode dar. $(R)$

A enfermeira busca a abrangência do cuidado à família, pois incorpora a necessidade da humanização no âmbito familiar, pela compreensão de que a construção da subjetividade do paciente está intrincada ao seio familiar, e o equilíbrio da família passa a depender do equilíbrio do estado de saúde e recuperação do paciente. Assim, o objeto do cuidado envolve o contexto familiar, ficando várias relações interpessoais nessa dependência. Portanto, ela interage, e busca proporcionar relação entre a família e o médico, e demais profissionais. A família quer que sejam realizadas todas as intervenções que forem necessárias para a cura da doença. Neste contexto, na unidade hospitalar sempre há médico de plantão, além dos cirurgiões especialistas que atuam em todo o hospital. A enfermeira interage com a família, mas compreende suas competências e espaço social de atuação profissional em respeito ao espaço dos demais profissionais, e desenvolve formas de encontro destes com familiares. O ser humano é visto como um organismo que tem que lidar com o que observa. Ele faz um objeto daquilo que observa, dá a ele um significado. $\mathrm{E}$ esse significado é utilizado na sua ação ${ }^{(15)}$.

\section{Interação da enfermeira com pacientes}

As enfermeiras interagem com os pacientes para realizar os cuidados de enfermagem direcionados ao indivíduo. Por exemplo, na realização de um curativo, na passagem de um cateter naso-gástrico ou na aspiração traqueo-brônquica de um paciente, há a interação. Quando o paciente se comunica verbalmente essa se concretiza com a conversa, explicações e/ou orientação como observamos nos depoimentos das participantes G e R:

(...) a interação é boa, acontece com conversa, a gente sempre avisar quando vai fazer o procedimento, avisar, responder (...) aí você chega e conversa, pra explicar que precisa tomar pra passar a dor (...) (R)

(...) às vezes ele [o paciente] tá querendo conversar com a gente, a maneira como a gente trata ele, né? Ele fica muito feliz, querendo até conversar com a gente, pega na mão da gente né, e conversa, conhece até a gente (...) (G)

A enfermeira relata manter um bom relacionamento com os pacientes ao realizar os cuidados de enfermagem. A forma como ela os trata é muito importante para que esse cuidado ocorra. Quando ela cuida, estabelece-se uma relação interpessoal saudável, amigável, e a relação de cuidado, da enfermira com os pacientes, torna-se mais autêntica, pois está permeada por ações e sentimentos. Cada pessoa está agindo. Ocorre a ação conjunta ou coletiva, onde os indivíduos adaptam suas linhas de ação umas às outras ${ }^{(15)}$.

$\mathrm{Na}$ unidade hospitalar, existem alguns pacientes que não contactuam verbalmente. Estes estão traqueostomizados, outros entubados e ainda outros sequelados neurologicamente, com prejuízos da atividade cognitiva. Mesmo assim, observamos nos depoimentos que as enfermeiras interagem com esses pacientes, como está transcrito abaixo:

(...) eu gosto de olhar todo o meu paciente, vê (...), conversar com ele, mesmo ele estando inconsciente eu acho importante você chegar e falar com a pessoa (...) você pegar na pessoa, - Olhe eu estou aqui, vou cuidar de você, vou passar a noite com o senhor (...) sou enfermeira, se você precisar de alguma coisa pode me procurar. (A)

Essa interação caminha no sentido de olhar, falar e pegar, conforme destacamos em negrito. A forma de agir da enfermeira junto aos pacientes emerge do contexto simbólico em que ela convive, dentro da unidade. São pacientes graves, que precisam de um suporte respiratório e, alguns, não contactuam verbalmente, mas a enfermeira precisa fazer o exame físico, e os seus cuidados de enfermagem. Apesar de o paciente estar com o prognóstico ruim, a enfermeira e sua equipe desenvolve o cuidado e conforto na alimentação, hidratação, higienização dentre outros cuidados rotineiros. A enfermeira estabelece essa interação não apenas com a comunicação verbal, mas principalmente a não verbal, olhando, falando e tocando. Desta forma ela utiliza estratégias de acordo com o que observa.

Às vezes assim (...) o psicológico, quando o paciente interage com a gente, que conversa... a gente conversa um pouquinho, tira uma brincadeira (...) (F)

A enfermeira diz algo engraçado, uma brincadeira, para estabelecer o contato inicial. A partir daí, vai conversando, desenvolvendo a relação interativa, até o estabelecimento da confiança. Essa forma de agir junto ao paciente tem como a finalidade o cuidado de enfermagem e visualiza o ser cuidado de forma mais completa e integral.

Eu acho que é tá do lado do paciente, conhecer o paciente, conhecer o que ele tem, o contexto dele (...) e olhar pro paciente, e ver o estado dele se é de dor, se não é. (M)

Ela acredita que seja importante conhecer as percepções dos pacientes, "ver o estado dele", "olhar para ele". Assim, a observação e ações vão sendo construídas. Os comportamentos das pessoas com relação ao que observam não é uma resposta elaborada pela apresentação do que observam, mas ao invés disso é uma ação que surgi da interpretação feita através do processo de auto interação ${ }^{(15)}$, a enfermeira observa, interpreta e interage consigo mesma para agir. 


\section{CONSIDERAÇÕES FINAIS}

Durante a realização dos cuidados de enfermagem na unidade investigada, observamos que as enfermeiras, ao interagir com as pessoas que fazem parte do ambiente hospitalar, vivenciam um cuidar interativo e humanístico, a partir das relações estabelecidas.

Além da pessoa que está recebendo o cuidado, existe um acompanhante, familiar ou não. Este fica perto, ajudando, observando, solicitando e sendo solicitado. Nesse sentido, a enfermeira, ao cuidar/interagir com o paciente, interage também com o acompanhante. Para cuidar, ela necessita da equipe de enfermagem, e dos demais profissionais da saúde. A interação social se faz necessária para a realização dos cuidados de enfermagem.

Assim, o cuidado da enfermeira depende da interação social com as pessoas que ali constituem o contexto da unidade: pacientes, acompanhantes, equipe de enfermagem, equipe multiprofissional e os demais presentes no ambiente do cuidado. O relacionamento interpessoal que estabelece torna-se significativo para o cuidado.

Desta forma, o cuidar envolve verdadeiramente uma ação interativa. Ao focalizarmos o cuidado de enfermagem, na perspectiva das enfermeiras, pudemos repensar a relação cuidativa do profissional com o paciente, atores nesse cenário, enfatizando a singularidade e integralidade de ambos.

Compreendemos que os cuidados de enfermagem disponibilizados aos pacientes no ambiente hospitalar é um ato complexo, carregado de elementos simbólicos, rico em significados, que fazem com que as enfermeiras direcionem suas ações levando sempre em consideração esses significados. A aproximação com a subjetividade das enfermeiras nos permitiu conhecer seu mundo de objetos, que permeiam o seu fazer cotidiano, proporcionando reflexão sobre estes significados e a prática do cuidado clínico de enfermagem.

Esperamos que esta pesquisa possa estimular a realização de outras, na compreensão de que o cuidado de enfermagem é algo dinâmico, e precisa ser estudado e entendido em profundidade, por quem se disponibiliza a cuidar de outros.

\section{REFERÊNCIAS BIBLIOGRÁFICAS}

1. Waldow VR. Cuidado humano: o resgate necessário. Porto Alegre: Sagra Luzzatto, 2001.

2. Carneiro TM. Vivenciando o cuidar e o curar como familiar em um hospital. Rev Bras Enferm 2008; 61(3): 390-4.

3. Neves EP. As dimensões do cuidar em enfermagem: concepções teórico-filosóficas. Esc Anna Nery Rev Enferm 2002; 6 (sup. 1): 79-92.

4. Boff L. O cuidado essencial: princípio de um novo ethos. Inclusão Social 2005; 1(1): 28-35.

5. Moura ACF, Rabêlo CBM, Sampaio MRFB. Prática profissional e metodologia assistencial dos enfermeiros em hospital filantrópico. Rev Bras Enferm 2008; 61 (4): 476-81.

6. Souza ACC, Filha MJMM, Silva LF, Monteiro, ARM, Fialho AVM. Formação do enfermeiro para o cuidado: reflexões da prática profissional. Rev Bras Enferm 2006; 59 (6): 805-7.

7. Mathias JJS. Cuidado transpessoal de enfermagem ao familiar cuidador da criança com neoplasia: um marco referencial [dissertação]. Curitiba (PR): Programa de Pós-Graduação em Enfermagem, Universidade Federal do Paraná; 2007.

8. Waldow VR. Cuidar expressão humanizadora da enfermagem. 2a. ed. Petrópolis, RJ: Vozes, 2007.

9. Ferreira MA. A comunicação no cuidado: uma questão fundamental na enfermagem. Rev Bras Enferm 2006; 59 (3): $327-30$

10. Paterson JG, Zderad LT. Humanistic nursing. New York (USA): National League for nursing, 1988.

11. George JB. Teorias de enfermagem: os fundamentos à prática profissional. 4a. ed. Porto Alegre: 2000. p. 241-51.

12. Castro ES, Mendes PW, Ferreira, MA. A interação no cuidado: uma questão na enfermagem fundamental. Esc
Anna Nery Rev Enferm 2005; 9 (1): 39-45.

13. Fonseca $A L N$, Lacerda MR, Maftum MA. O cuidado transpessoal de enfermagem no domicílio ao portador de transtorno mental e sua família. Cogitare Enferm 2006; 11 (1): 7-15.

14. Ayres JRCM. O cuidado, os modos de ser (do) humano e as práticas de saúde. Saude Soc 2004; 13 (3): 16-29.

15. Blumer $H$. Symbolic interactionism: perspective and method. California: University of California Press, 1969.

16. Lopes $\mathrm{CHAF}$, Jorge MSB. Interacionismo simbólico e a possibilidade para o cuidar interativo em enfermagem. Rev Esc Enferm USP 2005; 39 (1): 103-8.

17. Minayo MCS. Pesquisa social: teoria, método e criatividade. $21^{\text {a }}$ ed. Suely Ferreira Deslandes, Otavio Cruz Neto, Romeu Gomes; Maria Cecília de Souza Minayo (Orgs.). Petrópolis, RJ: Vozes, 2002.

18. Haguette TMF. Metodologias qualitativas na sociologia. 3a. ed. Rio de Janeiro: Vozes, 1992.

19. Gaskell G. Entrevistas individuais e grupais. In: Bauer MW, Gaskell G. Pesquisa qualitativa com texto, imagem e som: um manual prático. 2a. ed. Petrópolis, RJ: Vozes, 2002.

20. Bardin, L. Análise de Conteúdo. Lisboa: Edições 70, 1977.

21. Peduzzi M. Equipe multiprofissional de saúde: conceito e tipologia. Rev Saúde Pública 2001; 35 (1): 103-9.

22. Celich KLS, Crossetti MGO. Estar com o cuidador: dimensão do processo de cuidar. Rev Gaúcha Enferm 2004; 25(3): 377-85.

23. Backes DS, Koerich MS, Erdmann AL. Humanizando o cuidado pela valorização do ser humano: re-significação de valores e princípios pelos profissionais da saúde. Rev Latino-am Enfermagem 2007; 15 (1): 34-41. 